\title{
PENGARUH KENAIKAN KUAT GESER TANAH TERHADAP STABILITAS TIMBUNAN DI ATAS TANAH LEMPUNG LUNAK JENUH AIR
}

\author{
Candra Ismail Alhakim, dan Andryan Suhendra \\ ${ }^{1}$ Program Studi Sarjana Teknik Sipil, Universitas Tarumanagara, Jl. Letjen S. Parman No.1 Jakarta \\ Email: candraia29@gmail.com \\ ${ }^{1}$ Program Studi Sarjana Teknik Sipil, Universitas Tarumanagara, Jl. Letjen S. Parman No.1 Jakarta \\ Email: andryansuhendra@yahoo.com
}

\begin{abstract}
ABSTRAK
Proses konsolidasi tanah merupakan peristiwa yang berupa pemampatan tanah yang disebabkan oleh beban diatasnya maupun beban tanah sendiri. Peristiwa ini juga menyebabkan naiknya kuat geser tanah. Oleh karena itu di dalam skripsi ini dicoba untuk mensimulasikan beban berupa timbunan dan menganalisis akibat dari beban timbunan tersebut pada tanah lunak dibawahnya dan menganalisis hasil dari peningkatan kuat geser terhadap kestabilan timbunan. Penelitian dimulai dengan pengolahan data tanah untuk mendapatkan parameter void ratio, kemudian dilanjutkan dengan mencari peningkatan kuat geser berdasarkan peningkatan derajat konsolidasi, dan kemudian dilannjutkan dengan menghitung stabilitas timbunan pada setiap ketinggian kemudian didapatkan hasil angka keamanan pada tinggi timbunan $3 \mathrm{~m}$ sebesar 3,985 pada tinggi timbunan $5 \mathrm{~m}$ sebesar 2,961 dan pada tinggi $7 \mathrm{~m}$ sebesar 2,378.
\end{abstract}

Kata Kunci : Konsolidasi, Timbunan,, Kuat Geser

\section{PENDAHULUAN}

Ketika konsolidasi terjadi, tanah akan menjadi lebih padat dan akan mengalami peningkantan kuat geser dan daya tahan tanah akan meningkat (Lasitasih \& Tantri, 2015). Untuk itu jurnal ini bertujuan untuk menganalisa efek yang terjadi pada timbunan dengan tanah lunak yang sudah mengalami konsolidasi. Melalui perhitungan dengan menggunakan cara manual maupun software nantinya, bisa dilihat seberapa besar peningkatan daya dukung dan angka keamanan yang terjadi setelah tanah lunak yang diberi timbunan mengalami konsolidasi.

\section{TEGANGAN TANAH}

Bila beban diterapkan kepada tanah, maka beban tersebut akan dipikul oleh partikel tanah dan air yang terdapat di dalam pori-pori tanah. Tegangan vertikal total yang bekerja pada titik di bawah permukaan tanah, disebabkan oleh beratnya segala sesuatu yang ada di atasnya, termasuk berat sendiri tanah, berat air, dan pembebanan di permukaan. Berikut adalah rumus tegangan tanah.

$$
\sigma_{\mathrm{v}}=\gamma \cdot \mathrm{Z}
$$

keterangan

$\sigma_{\mathrm{v}}=$ Tegangan tanah total

$\gamma=$ Berat jenis tanah

$\mathrm{Z}=$ kedalaman tanah

\section{TEGANGAN TANAH EFEKTIF}

Apabila tanah diberi beban, maka tanah akan mendapat tekanan yang disebabkan oleh beban. Hal tersebut akan mengakibatkan angka pori tanah berkurang dan menambah tahanan geser tanah. Jika tanah berada di dalam air misalkan tanah terendam oleh air tanah, tanah akan dipengaruhi oleh gaya angkat yang diakibatkan oleh tekanan hidrostatis dari air. Berat tanah yang terendam ini disebut berat tanah efektif, sedangkan tegangan yang terjadi karena berat tanah efektif di dalam tanah disebut sebagai tegangan efektif. Terzaghi (Darwin, 2018) memberikan prinsip tegangan efektif yang bekerja pada segumpal tanah. Prinsip tegangan efektif hanya berlaku pada tanah yang jenuh sempurna yaitu

- $\quad$ Tegangan normal total $(\sigma)$ pada suatu bidang di dalam massa tanah, yaitu tegangan akibat berat tanah total termasuk air dalam ruang pori per satuan luas, yang arahnya tegak lurus.

- Tekanan pori (u), disebut juga dengan tekanan netral yang bekerja ke segala arah sama besar, yaitu tekanan air yang mengisi rongga di antara butiran padat. 
- $\quad$ Tegangan normal efektif ( $\sigma^{\prime}$ ) pada suatu bidang di dalam massa tanah, yaitu tegangan yang dihasilkan dari beban berat butiran tanah per satuan luas bidangnya.

Hubungan dari ketiganya dirumuskan sebagai berikut.

keterangan

$$
\sigma_{\text {total }}=\sigma^{\prime}+\mathrm{u}
$$

$\sigma_{\mathrm{v}} \quad=$ Tegangan tanah total

$\gamma \quad=$ Berat jenis tanah

$\mathrm{Z} \quad=$ kedalaman tanah

$\mathrm{u} \quad=$ tegangan air pori

Kemudian untuk tegangan air yang terdapat di dalam tanah maka dapat dirumuskan sebagai berikut.

$$
\mathrm{u}=\gamma_{\mathrm{w}} \cdot \mathrm{h}
$$

keterangan

$$
\begin{array}{ll}
\mathrm{u} & =\text { tegangan air pori } \\
\gamma_{\mathrm{w}} & =\text { Berat jenis air } \\
\mathrm{h} & =\text { kedalaman di bawah permukaan air atau ketebalan air di atas titik yang ditinjau }
\end{array}
$$

Berikut adalah gambar ilustrasi mengenai gaya antar butiran pada segumpal tanah dan kontak antar butiran.

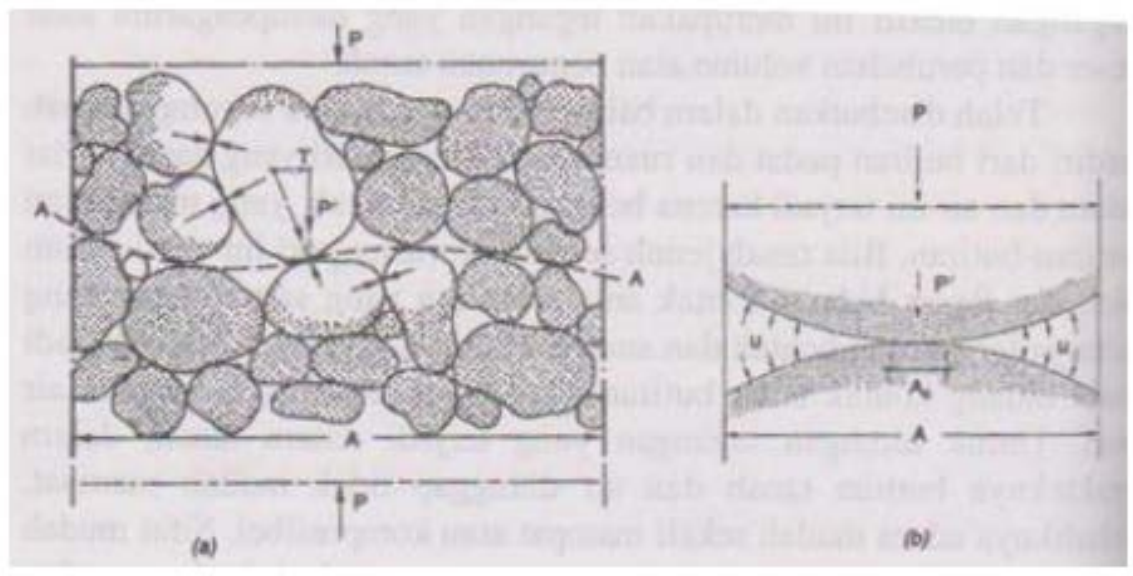

Gambar 1. Ilustrasi gaya antar butiran pada segumpal tanah (a) dan ilustrasi kontak antar butiran (b) (Darwin,2018)

Apabila tanah berada di bawah muka air atau bisa disebut jenuh maka tegangan vertikal total adalah tegangan normal pada bidang horizontal pada kedalaman z yang merupakan berat seluruh bagian tanah (padat + air) per satuan luas yang bisa dirumuskan dengan rumus berikut.

keterangan

$$
\sigma_{\mathrm{v}}=\gamma_{\mathrm{sat}} \cdot \mathrm{Z}
$$

$\sigma_{\mathrm{v}} \quad=$ Tegangan total jenuh

$\gamma_{\text {sat }} \quad=$ Berat volume tanah jenuh

$\mathrm{Z} \quad=$ kedalaman tanah yang ditinjau

Dan untuk tegangan efektif dapat dirumuskan sebagai berikut.

keterangan

$$
\begin{aligned}
\sigma_{\mathrm{v}}{ }_{\mathrm{v}} & =\sigma_{\mathrm{v}}-\mathrm{u} \\
& =\gamma_{\mathrm{sat}} \cdot \mathrm{Z}-\gamma_{\mathrm{w}} \cdot \mathrm{Z} \\
& =\left(\gamma_{\mathrm{sat}}-\gamma_{\mathrm{w}}\right) \cdot \mathrm{Z} \\
& =\gamma^{\prime} \cdot \mathrm{Z}
\end{aligned}
$$

$\sigma_{\mathrm{v}} \quad=$ Tegangan total jenuh

$\gamma_{\text {sat }}=$ Berat volume tanah jenuh

$\mathrm{Z} \quad=$ kedalaman tanah yang ditinjau

$\gamma_{\mathrm{w}} \quad=$ Berat jenis air

Dan berikut adalah gambar teganganefektif pada suatu lapisan tanah. 


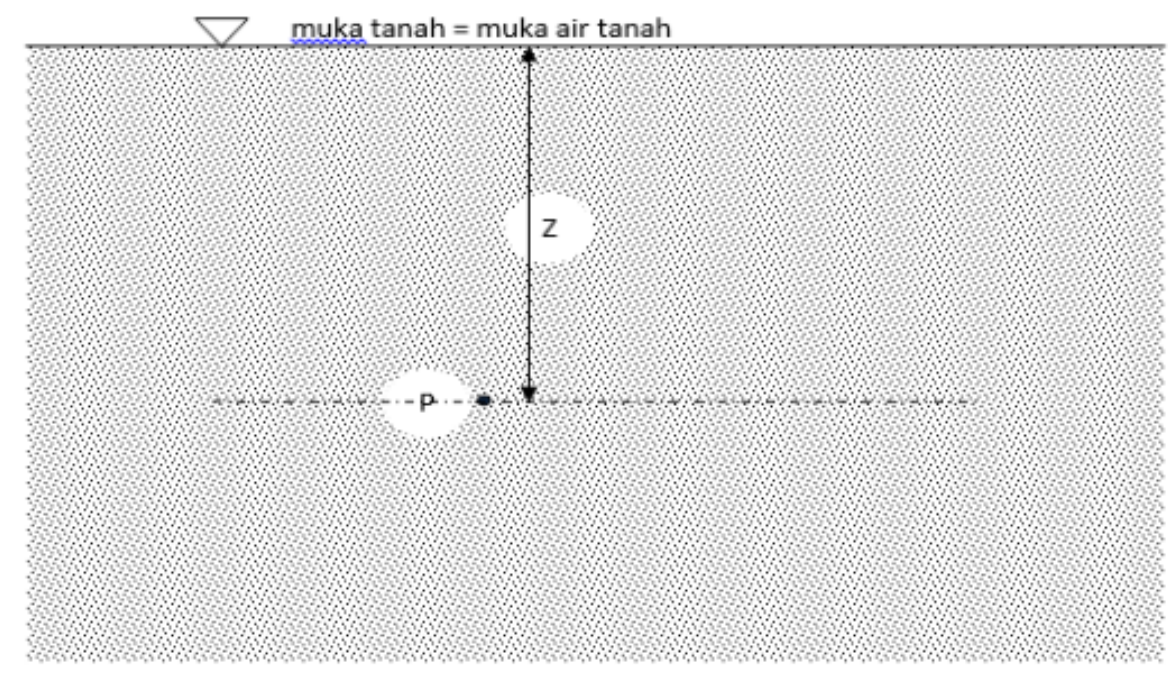

Gambar 2 Tegangan efektif pada suatu lapisan tanah (Darwin, 2018)

\section{PENYEBARAN TEGANGAN}

Tegangan di dalam tanah yang timbul akibat adanya beban di permukaan dinyatakan dalam istilah tambahan tegangan (stress increment), karena sebelum tanah dibebani, tanah sudah mengalami tekanan akibat beban tanah sendiri disebut tekanan overburden (Darwin, 2018).

\subsection{Teori Boussinesq}

Boussinesq (Darwin, 2018) memberikan persamaan penyebaran beban akibat pengaruh beban titik di permukaan. Tambahan tegangan vertikal $\left(\Delta \sigma_{\mathrm{z}}\right)$ akibar beban titik dianalisis dengan meninjau system tegangan pada koordinat silinder.

\subsubsection{Akibat Beban Trapesium}

Boussinesq menggambarkan tegangan yang disebabkan oleh Trapesium sebagai berikut.

b

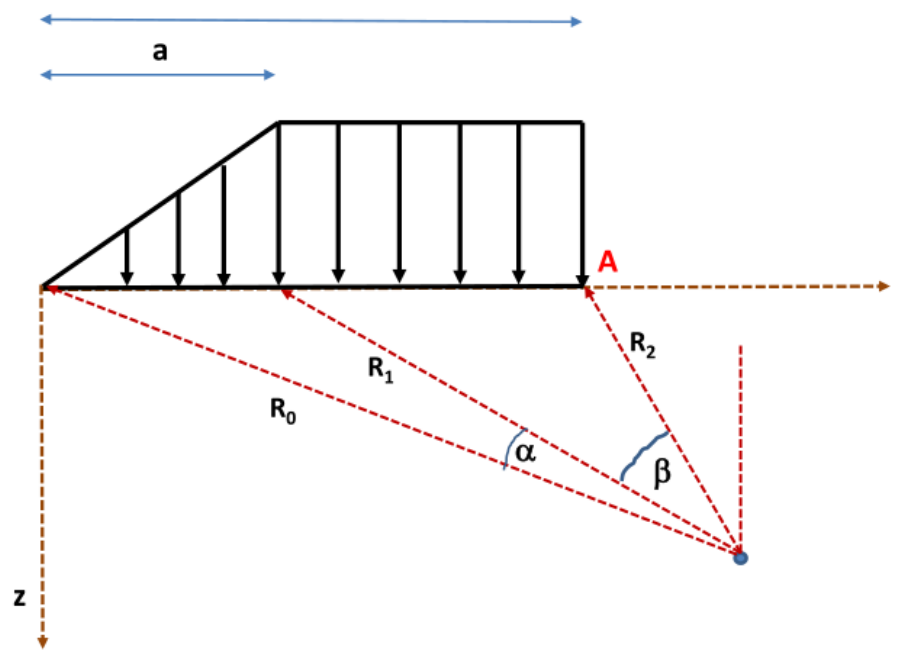

Gambar 3 Bentuk Pembebanan Trapesium (Darwin, 2018)

Kemudian besar tambahan tegangan vertikal didapat dari rumus yang sudah disederhanakan sebagai berikut. 


$$
\Delta \sigma_{z}=q . I
$$

Keterangan

q = tekanan akibat beban merata di permukaan

I = faktor pengaruh tegangan vertikal

Dimana nilai I didapat dari grafik berikut.

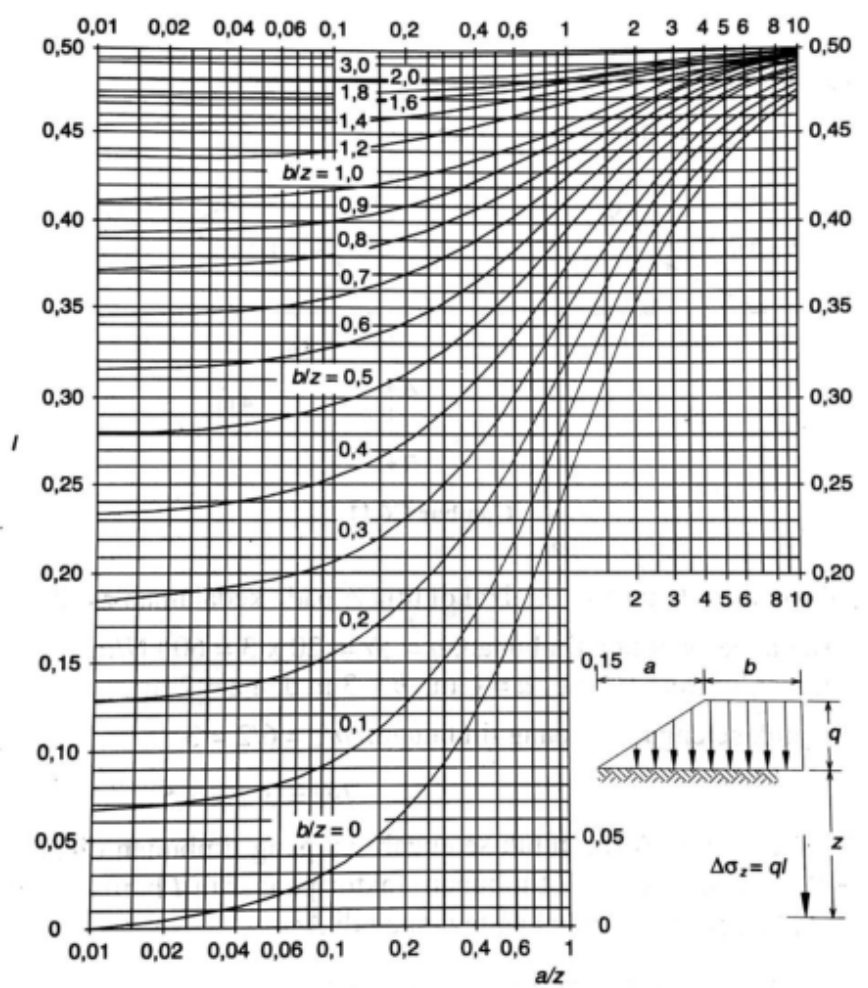

Gambar 4 Grafik faktor pengaruh (I) akibat beban trapezium (Darwin, 2018)

\section{PENURUNAN KONSOLIDASI}

Konsolidasi tanah adalah proses pemampatan tanah yang disebabkan adanya beban maupun pemampatan natural tanah karena properties tanah itu sendiri. Tanah lunak merupakan tanah kohesif yang sebagian besar terdiri dari butir-butir yang sangat kecil seperti lempung dan lanau. Lapisan tanah lunak mempunyai sifat gaya geser yang rendah, kemampatan yang tinggi, koefisien permeabilitas yang rendah, dan mempunyai daya dukung yang rendah (Siska,2016).

Berikut adalah rumus yang digunakan untuk menghitung konsolidasi tanah.

Untuk Konsolidasi Normal

Untuk Overlly Consolidated

$$
S p=\frac{C c . H}{1+e o} \log \left(\frac{\sigma^{\prime} o+\Delta \sigma \prime}{\sigma^{\prime} o}\right)
$$

Untuk kondisi $\sigma^{\prime} o+\Delta \sigma^{\prime} \leq \sigma^{\prime} p$

Untuk kondisi $\sigma^{\prime} o+\Delta \sigma^{\prime} \geq \sigma^{\prime} p$

$$
S p=\frac{C r \cdot H}{1+e o} \log \left(\frac{\sigma^{\prime} o+\Delta \sigma \prime}{\sigma^{\prime} o}\right)
$$

$$
S p=\frac{C r . H}{1+e o} \log \left(\frac{\sigma^{\prime} p c}{\sigma^{\prime o}}\right)+\frac{C c . H}{1+e o} \log \left(\frac{\sigma^{\prime} o+\Delta \sigma^{\prime}}{\sigma^{\prime o}}\right)
$$

Keterangan :

$$
\begin{array}{ll}
\mathrm{Sp} & =\text { penurunan konsolidasi } \\
\mathrm{Cc} & =\text { koefisien konsolidasi untuk Normally Consolidated } \\
\mathrm{Cr} & =\text { koefisien konsolidasi untuk Overlly Consolidated } \\
\mathrm{e}_{0} & =\text { angka pori awal } \\
\sigma_{0} & =\text { tegangan efektif awal } \\
\Delta \sigma_{0} & =\text { perubahan tegangan efektif vertikal }
\end{array}
$$


$\sigma_{\mathrm{pc}}^{\prime} \quad=$ tegangan pra konsolidasi

\section{KUAT GESER TANAH}

Kuat geser tanah adalah gaya tahan internal yang dapat diberikan tanah oleh berat tanah. Mohr (1900) mengemukakan teori bahwa kegagalan material disebabkan oleh kombinasi kritis dari gaya normal dan gaya geser dan tidak hanya dari gaya normal maksimum ataupun haya gaya geser maksimum. Berdasarkan teori tersebut MohrCoulomb merumuskan rumus untuk menghitung gaya geser tanah yaitu:

Keterangan :

$$
\tau \mathrm{f}=\mathrm{c}+\sigma \tan \phi
$$

$$
\begin{array}{ll}
\tau \mathrm{f} & =\text { kuat geser } \\
\mathrm{c} & =\text { kohesi tanah } \\
\varnothing & =\text { sudut geser tanah }
\end{array}
$$

Dan berikut adalah rumus peningkatan kuat geser tanah yang digunakan dalam jurnal ini.

Mesri (1975) dan Balasubramaniam (1991)

$$
\left(\frac{\Delta \mathrm{Su}}{\sigma \prime \mathrm{p}}\right)=0,22
$$

Keterangan :

$$
\begin{array}{ll}
\Delta \mathrm{Su} & =\text { Pertambahan Kuat Geser } \\
\mathrm{U} & =\text { Derajat Konsolidasi }
\end{array}
$$

\section{PERHITUNGAN STABILITAS LERENG DENGAN METODE SWEDISH CIRCLE}

Di dalam metode Swedish Circle, bidang selip diasumsikan sebagai busur lingkaran dan momen diasumsikan di tengah lingkaran untuk menghitung angka keamanan. Sebagian bentuk dari metode ini pertama digunakan oleh Petterson pada tahun 1916, namun metode ini pertama di formalisasikan untuk $\varnothing=0$ oleh fellenius pada tahun 1922. Sudut geser tanah diasumsikan sebagai 0 dan kuat geser diasumsikan dari kohesi. Untuk itu metode Swedish Circle juga disebut sebagai metode $\varnothing=0$ (Duncan, 2014).

Untuk mennghitung angka keamanan, digunakan rumus berikut.

Keterangan

$$
F=\frac{\sum c . \Delta l}{\sum W \sin a}
$$

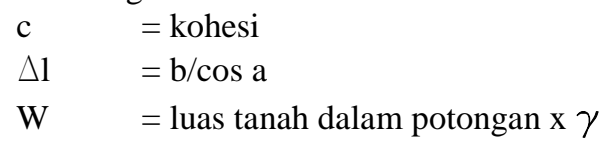

Berikut adalah gambar potongan timbuan dengan menggunakan metode Swedish Circle

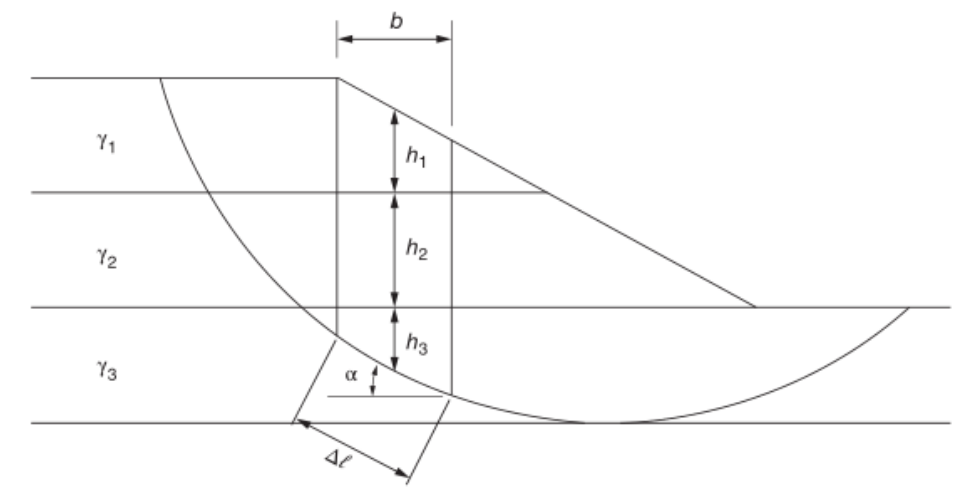

Gambar 5 Potongan melintang menurut method Swedish Circle (Darwin,2018) 


\section{DATA TANAH TIMBUNAN}

Berikut adalah data tanah asumsi yang digunakan sebagai data tanah timbunan yang digunakan dalam skripsi ini :

$\gamma$ wet $=20,5 \mathrm{kN} / \mathrm{m}^{3}$

$\gamma \mathrm{d} \quad=17,4 \mathrm{kN} / \mathrm{m}^{3}$

$\mathrm{c} \quad=50 \mathrm{kN} / \mathrm{m}^{2}$

$\varnothing \quad=20,16^{\circ}$

\section{DATA TANAH DASAR}

Berikut adalah data tanah dasar

Tabel 1. Data Tanah Dasar

\begin{tabular}{ccccccccc}
\hline Depth & $\gamma_{\text {wet }}(\mathrm{kN} / \mathrm{m} 3)$ & $\gamma_{\mathrm{d}}(\mathrm{kN} / \mathrm{m} 3)$ & $\mathrm{n}$ & $\mathrm{Cu}(\mathrm{kN} / \mathrm{m} 2)$ & $\varnothing$ & $\mathrm{Cc}$ & $\mathrm{Cv}\left(\mathrm{cm}^{2} / \mathrm{s}\right)$ & $\sigma^{\prime}{ }_{\mathrm{pc}}\left(\mathrm{kN} / \mathrm{m}^{2}\right)$ \\
\hline $1,00-1,55$ & 16,62 & 9,29 & 0,57 & 14,1 & 8,28 & 0,427 & 0,0566 & 83 \\
\hline $3,00-3,55$ & 15,88 & 8,99 & 0,59 & 9,8 & 3,9 & 0,434 & 0,0097 & 167 \\
\hline $11,00-11,55$ & 17,39 & 10,85 & 0,51 & 12,3 & 2,19 & 0,344 & 0,00242 & 125 \\
\hline $15,00-15,55$ & 17,68 & 11,79 & 0,48 & 37 & 1,15 & 0,249 & 0,00203 & 149 \\
\hline
\end{tabular}

\section{PERHITUNGAN PENURUNAN KONSOLIDASI}

Tabel 2 Perhitungan Penurunan Konsolidasi Tanah

\begin{tabular}{ccccccc}
\hline Lapisan Tanah & Beban 3 m $(\mathrm{kN} / \mathrm{m})$ & Beban 5 m $(\mathrm{kN} / \mathrm{m})$ & Beban 7 m $(\mathrm{kN} / \mathrm{m})$ & Sp 3m & Sp 5m & Sp 7m \\
\hline Lapisan 1 & 44,89 & 85,26 & 121,80 & 0,0493 & 0,0652 & 0,0746 \\
\hline Lapisan 2 & 33,41 & 73,08 & 104,75 & 0,0462 & 0,0776 & 0,0952 \\
\hline Lapisan 3 & 22,97 & 57,42 & 80,39 & 0,0200 & 0,0420 & 0,0535 \\
\hline Lapisan 4 & 21,92 & 46,98 & 77,95 & 0,0080 & 0,0154 & 0,0230 \\
\hline & & & 0,1234 & 0,2002 & 0,2464 \\
\cline { 3 - 6 }
\end{tabular}




\section{PERHITUNGAN KENAIKAN KUAT GESER}

Tabel 3 Perhitungan Kenaikan Kuat Geser

\begin{tabular}{|c|c|c|c|c|c|c|c|c|c|}
\hline \multirow{2}{*}{ lapisan tanah } & \multicolumn{3}{|c|}{ Timbunan 3 m } & \multicolumn{3}{|c|}{ Timbunan $5 \mathrm{~m}$} & \multicolumn{3}{|c|}{ Timbunan $7 \mathrm{~m}$} \\
\hline & $\sigma^{\prime} \mathrm{p}(25 \%)$ & $\Delta \mathrm{Su}$ & Su Akhir & $\sigma^{\prime} \mathrm{p}(25 \%)$ & $\Delta \mathrm{Su}$ & Su Akhir & $\sigma^{\prime} \mathrm{p}(25 \%)$ & $\Delta \mathrm{Su}$ & Su Akhir \\
\hline Lapisan 1 & 15,2213 & 3,3487 & 17,4487 & 17,4727 & 3,8440 & 17,9440 & 18,9510 & 4,1692 & 18,2692 \\
\hline Lapisan 2 & 40,9267 & 9,0039 & 18,8039 & 45,9117 & 10,1006 & 19,9006 & 48,9693 & 10,7733 & 20,5733 \\
\hline Lapisan 3 & 72,8644 & 16,0302 & 28,3302 & 78,9718 & 17,3738 & 29,6738 & 82,3693 & 18,1213 & 30,4213 \\
\hline \multirow[t]{2}{*}{ Lapisan 4} & 102,8023 & 22,6165 & 59,6165 & 107,8067 & 23,7175 & 60,7175 & 113,1626 & 24,8958 & 61,8958 \\
\hline & $\sigma^{\prime} \mathrm{p}(50 \%)$ & & & $\sigma^{\prime} \mathrm{p}(50 \%)$ & & & $\sigma^{\prime} \mathrm{p}(50 \%)$ & & \\
\hline Lapisan 1 & 23,3320 & 5,1330 & 19,2330 & 30,7447 & 6,7638 & 20,8638 & 36,1674 & 7,9568 & 22,0568 \\
\hline Lapisan 2 & 48,4662 & 10,6626 & 20,4626 & 60,9921 & 13,4183 & 23,2183 & 69,3865 & 15,2650 & 25,0650 \\
\hline Lapisan 3 & 78,3822 & 17,2441 & 29,5441 & 92,0727 & 20,2560 & 32,5560 & 100,1654 & 22,0364 & 34,3364 \\
\hline \multirow[t]{2}{*}{ Lapisan 4} & 108,1378 & 23,7903 & 60,7903 & 118,9223 & 26,1629 & 63,1629 & 131,0321 & 28,8271 & 65,8271 \\
\hline & $\sigma^{\prime} \mathrm{p}(75 \%)$ & & & $\sigma^{\prime} \mathrm{p}(75 \%)$ & & & $\sigma^{\prime} \mathrm{p}(75 \%)$ & & \\
\hline Lapisan 1 & 35,7646 & 7,8682 & 21,9682 & 54,0979 & 11,9015 & 26,0015 & 69,0241 & 15,1853 & 29,2853 \\
\hline Lapisan 2 & 57,3947 & 12,6268 & 22,4268 & 81,0259 & 17,8257 & 27,6257 & 98,3163 & 21,6296 & 31,4296 \\
\hline Lapisan 3 & 84,3178 & 18,5499 & 30,8499 & 107,3469 & 23,6163 & 35,9163 & 121,8064 & 26,7974 & 39,0974 \\
\hline \multirow[t]{2}{*}{ Lapisan 4} & 113,7503 & 25,0251 & 62,0251 & 131,1840 & 28,8605 & 65,8605 & 151,7234 & 33,3791 & 70,3791 \\
\hline & $\sigma^{\prime} \mathrm{p}(90 \%)$ & & & $\sigma^{\prime} \mathrm{p}(90 \%)$ & & & $\sigma^{\prime} \mathrm{p}(90 \%)$ & & \\
\hline Lapisan 1 & 46,2120 & 10,1666 & 24,2666 & 75,9324 & 16,7051 & 30,8051 & 101,7211 & 30,8051 & 36,4786 \\
\hline Lapisan 2 & 63,5231 & 13,9751 & 23,7751 & 96,0802 & 21,1376 & 30,9376 & 121,1814 & 30,9376 & 36,4599 \\
\hline Lapisan 3 & 88,0929 & 19,3804 & 31,6804 & 117,7022 & 25,8945 & 38,1945 & 136,9751 & 38,1945 & 42,4345 \\
\hline Lapisan 4 & 117,2566 & 25,7965 & 62,7965 & 139,1398 & 30,6108 & 67,6108 & 165,6751 & 67,6108 & 73,4485 \\
\hline
\end{tabular}

\section{PERHITUNGAN KESTABILAN TIMBUNAN}

Tabel 4 Angka Keamanan Timbunan Berdasarkan Perhitungan

\begin{tabular}{ccccccc}
\hline Safety Factor & \multicolumn{3}{c}{ Software } & \multicolumn{3}{c}{ Manual } \\
\hline Derajat Konsolidasi & Timbunan 3m & Timbunan 5 m & Timbunan 7 m & Timbunan 3m & Timbunan 5 m & Timbunan 7 m \\
\hline 0 & 2,786 & 1,937 & 1,383 & 3,6412 & 2,4971 & 1,6139 \\
\hline $25 \%$ & 3,228 & 2,245 & 1,727 & 3,9268 & 2,7858 & 1,9147 \\
\hline $50 \%$ & 3,458 & 2,332 & 1,794 & 4,0790 & 2,9799 & 2,1020 \\
\hline $75 \%$ & 3,759 & 2,671 & 2,21 & 4,3123 & 3,2883 & 2,4213 \\
\hline $90 \%$ & 3,985 & 2,961 & 2,378 & 4,5084 & 3,5579 & 2,7165 \\
\hline
\end{tabular}




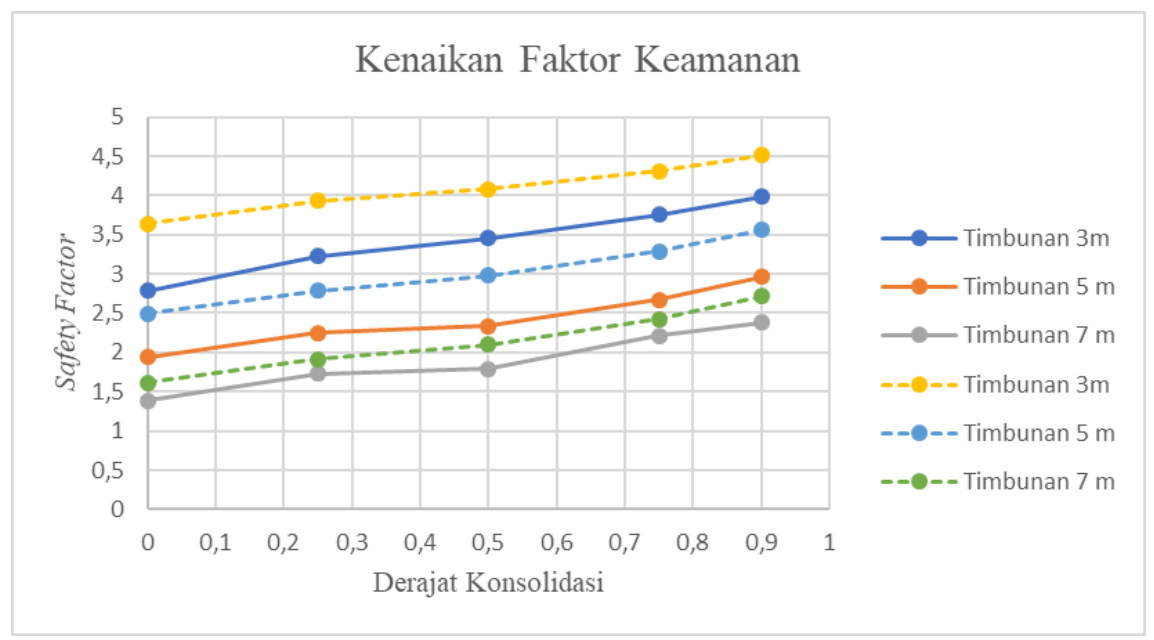

Gambar 6 Grafik Kenaikan Faktor Keamanan

Garis putus - putus menunjukkan perhitungan dengan menggunakan cara manual dan garis lurus menunjukkan perhitungan dengan menggunakan Software.

\section{KESIMPULAN}

Berikut adalah kesimpulan dari jurnal ini.

1. Persentase kenaikan angka keamanan pada perhtungan menggunakan cara manual lebih kecil $10 \%-20 \%$ ketimbang persentase kenaikan angka keamanan pada perhitungan dengan menggunakan Software.

2. Berdasarkan tabel persentase kenaikan angka keamanan, semakin tinggi timbunan, maka kenaikan angka keamanan yang disebabkan oleh kenaikan kuat geser tanah akan semakin besar.

3. Berdasarkan tabel kestabilan timbunan, semakin besar derajat konsolidasi, maka angka keamanan yang didapatkan akan semakin besar

4. Berdasarkan tabel kenaikan kuat geser, kenaikan kuat geser antar timbunan hanya berbeda sekitar 4,5\% dari timbunan tinggi $3 \mathrm{~m}$ ke timbunan tinggi $5 \mathrm{~m}$ ke timbunan tinggi $7 \mathrm{~m}$.

\section{DAFTAR PUSTAKA}

Darwis (2018). Dasar - Dasar Mekanika Tanah. Yogyakarta : Pustaka AQ.

Duncan, M (2014). Soil Strength and Slope Stability. New Jersey : John Wiley \& Sons.

Hardiani, Dyah (2018). Analisis Perkuatan Tanah Timbunan Pada Pelebaran Jalan di Ruas Jalan Veteran. 4.2655 4453

Lastiasih, Y \& Tantri,P (2015). Analysis of Increasing Shear Strength of Soil to Slope Stabiility After Consolidation Settlement Completed With Various Method.2

Siska, H (2016). Karakteristik Sifat Fisis dan Mekanis Tanah Lunak di Gedebage. 2. 